\title{
Aeromonas hydrophila Suşlarının Antibiyotik Direnç Profilleri
}

\author{
Nurdan FİLIK ${ }^{1 *}$, Ebru ÖNEM ${ }^{2} \mathbb{D}$, Ayşegül KUBİLAY $^{1} \mathbb{D}$ \\ ${ }^{1}$ Isparta Uygulamalı Bilimler Üniversitesi, Eğirdir Su Ürünleri Fakültesi, Hastalıklar Anabilim Dalı, Isparta \\ ${ }^{2}$ Süleyman Demirel Üniversitesi, Eczacılık Fakültesi, Farmasötik Mikrobiyoloji Anabilim Dalı, Isparta,
}

*Sorumlu Yazar: nurdansal@hotmail.com

Geliş 09 Eylül 2020; Kabul 22 Ekim 2020; Basım 01 Haziran 2021.

Alıntılama: Filik, N., Önem, E. \& Kubilay, A. (2021). Aeromonas hydrophila suşlarının antibiyotik direnç profilleri. Acta Aquatica Turcica, 17(2), 202-213. https://doi.org/10.22392/actaquatr.792224

\section{Özet}

Aeromonas hydrophila virülens özellikleri açısından önemli bir patojen olup balıklarda ölümcül bir hastalık olan Motile Aeromonas Septisemisine (MAS) neden olur. Bu çalışmada hasta balıklardan izole edilen 20 A. hydrophila suşunun ve A. hydrophila ATCC 7966 suşunun 28 farklı antibiyotiğe karşı duyarlılı̆̆ı araştırılmıştır. Araştırmada A. hydrophila suşlarında antibiyotik duyarlılık profilleri Kirby-Bauer disk difüzyon yöntemiyle saptanmış ve heri bir suşa ait Çoklu Antibiyotik Dirençliliği (ÇAD) indeksi hesaplanmıştır. Elde edilen sonuçlara göre suşların 12 antibiyotiğe dirençli, 14 antibiyotiğe duyarlı, 2 antibiyotiğe orta dercede duyarlı olduğu belirlenmiştir. ÇAD indeksi sonuçlarına göre suşların toplam 14 antibiyotiğe karşı çoklu antibiyotik direnci gösterdiği tespit edilmiştir. Suşların ÇAD indeks değerleri 0,21-0,75 aralığında tespit edilmiştir. Son yıllarda yapılan çalışmaların ortaya koyduğu bir bulgu A. hydrophila'nın oksitetrasikline karşı geliştirdiği dirençtir. Bu açıdan araştırma bulgularında en dikkat çeken oksitetrasiklin direnci olmuştur. A. hydrophila suşlarının araştırmada kullanılan antibiyotiklerin büyük bir kısmına ve yapılan bazı çalışmalarla tedavide en etkili antibiyotik olduğu bildirilen oksitetrasikline karşı direnç geliştirdiğinin tespit edilmesi suşların direnç profilinin yüksek olduğunu göstermektedir.

Sonuç olarak, balık patojenlerinin oluşturduğu hastalıkların tedavisinde yanlış antibiyotik kullanımı sonucu patojenin direnç kazandığı, bu durumunda balık hastalıkları ile mücadelede ciddi bir sorun oluşturduğu görülmektedir.

Anahtar Kelimeler: Aeromonas hydrophila, Balık, Antibiyogram, Çoklu Antibiyotik Dirençliliği, CLSI

\section{Antibiotic Resistance Profiles of Aeromonas hydrophila Strains}

\section{Abstract}

Aeromonas hydrophila virulent is a pathogen with important virulent properties and causes Motile Aeromonas Septicemia (MAS), a deadly disease in fish. In this study sensitivity of 20 A. hydrophila strains and A. hydrophila ATCC 7966 strains isolated from sick fish to 28 different antibiotics were investigated. In the study, antibiotic susceptibility profiles of A. hydrophila strains were determined by Kirby-Bauer disk diffusion method and the Multiple Antibiotic Resistance (MAR) index for each strain was calculated. According to the results, it was determined that the strains were resistant to 12 antibiotics, sensitive to 14 antibiotics, and 2 antibiotics moderately. According to the results of the MAR index, the strains were found to have multiple antibiotic resistance against the total of 14 antibiotics. MAR index values of strains were determined in the range of 0.21-0.75. One of the findings of recent studies is the resistance developed by A. hydrophila against oxytetracycline. In this respect, oxytetracycline resistance was the most striking in the research findings. The fact that A. hydrophila strains developed resistance to most of the antibiotics used in the research and oxytetracycline, which was reported to be the most effective antibiotic in treatment, shows that the resistance profile of strains is high.

As a result, it is seen that pathogen has gained resistance as a result of the use of broad-spectrum antibiotics in the treatment of diseases caused by fish pathogens, and this situation creates a serious problem in the fight against fish diseases.

Keywords: Aeromonas hydrophila, Fish, Antibiogram, Multiple Antibiotic Resistance, CLSI

\section{GíRIŞ}

A. hydrophila $28^{\circ} \mathrm{C}$ 'de optimal üreyen ancak $4^{\circ} \mathrm{C}$ ile $37^{\circ} \mathrm{C}$ arasındaki sicaklıklarda da üreyebilen firsatçı bir bakteridir (Agger vd., 2018). A. hydrophila, açık yaralar yoluyla, su veya yiyeceklerle yeterli sayıda organizmanın yutulması yoluyla balıklarda, amfibiyanlarda ve insanlarda hastalıklara neden olabilir. A. hydrophila çiğ sebzelerden de izole edilmiştir (Harris vd., 2003).

Patojenik olarak değerlendirildiğinde A. hydrophila hem balıklarda (Austin ve Austin, 2016; Rehulka, 2002) hem de insanlarda hastalık oluşturan zoonoz bir bakteridir (Castro, 2002; Davies vd., 
2001, Lehone ve Rawlin, 2000; Werner ve Rutherford, 1990). Aeromonas türleri balıklarda Hareketli Aeromonas Septisemi (Motile Aeromonas Septisemisi: MAS) hastalığına neden olur ve bu hastalık ciddi mortaliteyle sonuçlanır (Austin ve Austin, 2016). A. hydrophila hemorajik septisemisi Motile Aeromonas Septicemia ''Red Fin Disease', ''Red Pest', ''Infectious Abdominal Dropsy' adlar1 da literatürlere geçmiş olup (Roberts ve Shepherd, 2001; Öztürk ve Altınok, 2014) 1-2 hafta gibi kısa bir sürede \%80-100 ölüm oranıyla sonuçlandığı bilinmektedir (Lukistyowati, 2012; Kusdarwati vd., 2017). MAS hastalığının en önemli semptomları balıklarda deri ve kaslarda kanama şeklinde, karaciğer, böbrek ve dalakta hiperemi, iç organlarda doku kaybı, dropsi, ülserler, yüzgeç kaybı, epidermiste hiperplazi, ağız çevresinde erozyonlar, periorbital ödem, ekzoftalmus olarak görülmektedir (Mancini vd., 1997; Erer, 2002; Sağlam vd., 2006).

A. hydrophila'da antibiyotik direnci ve A. hydrophila kaynaklı hastalıklarda risk yönetim stratejileri incelendiğinde $A$. hydrophila yüksek genetik heterogenezis gösterdiği için bu hastalığa karşı koruyucu aşı ve probiyotik gibi profilaktif uygulamaların hastalığın kontrolü açısından zorluk oluşturduğu bildirilmektedir (Poobalane vd., 2010). Ülkemizde hareketli Aeromonas septisemi etkenleri de yaygın olarak izole edilmiştir (Baran vd., 1980; Timur, 1983; Güvener, 2001; Öztürk, 2007; Durmaz ve Türk, 2009; Korun ve Toprak, 2010; Boran, 2013; Onuk vd., 2013). Antibiyotiklerin yaygın kullanımı, balık ve çevresel patojenlere karşı antimikrobiyal direnç gelişimine neden olmaktadır (Angulo ve Griffin, 2000; Witte, 2000; Petersen vd., 2002; Angulo vd., 2004; Alcaide vd.,2005). Balık patojenlerinde antimikrobiyal direncin ortaya çıkması akuakültürde hastalıkların tedavisinde kullanılan antimikrobiyallerin etkisinin azalmasına, antimikrobiyal direnç geliştirmiş olan patojenlerin ve direnç genlerinin karasal hayvanlara, insanlara geçişine neden olabilmektedir (L'AbeeLund ve Sorum, 2001; Sorum, 2006; Duman 2017). Dolayısıyla antibiyotik direnci, dünya çapında modern tıbbın karşılaştığı en büyük zorluklardan biridir (Andersson vd., 2020). Bazı antimikrobiyaller balıklarda immun sistemin baskılanmasına neden olmakta ve buna bağlı olarak hastalıkların oluşumuna yol açmaktadır (Naylor ve Burke, 2005; Cabello, 2006). Antibiyotiklere karşı dirençli bakteri populasyonların ortaya çımasıyla antibiyotikler artık etkisiz kalmakta ve hastalıklar tam anlamiyla tedavi edilememektedir (Rasko ve Sperandio, 2010).

Ülkemizde streptomisin, oksitetrasiklin, trimetoprim ve nitrofurantoin gibi antibiyotiklere karş1 Motil Aeromonaslar'ın oldukça direnç kazandıkları saptanmıştır (Durmaz ve Türk, 2009). Antibiyotiklere bu denli direnç kazanmış $A$. hydrophila'yla mücadelede artık yeni stratejilerin belirlenmesi kaçınılmaz hale gelmiştir.

$\mathrm{Bu}$ makalenin amacı $A$. hydrophila'nın neden olduğu hastalıklarla mücadelede ilk akla gelen stratejilerden biri olan antibiyotiklerden sıklıkla kullanılan 28 antibiyotiğe karş1 20 A. hydrophila suşunun antibiyotik diren profillerinin belirlenmesi, ayrıca çoklu antibiyotik dirençliliği indekslerinin saptanması ve sonuçların litüratürlere geçmesiyle tedavi sürecinde başarıyı artırmaya yön vermektir.

\section{MATERYAL VE YÖNTEM}

\section{Materyal}

\section{Kullanılan antibiyotikler}

Antibiyogram testinde Gram negatif bakterilerin neden olduğu hastalıkların tedavisinde en çok tercih edilen ve literatür taramasında en çok kullanıldığı belirlenen 28 farklı Oxoid marka antibiyotikler kullanılmıştır (Tablo 1). 
Tablo1. Araştırmada kullanılan antibiyotikler

\begin{tabular}{lccc}
\hline Antibiyotik & Antibiyotik kodu & Antibiyotik dozu & Antibiyotik markası \\
\hline Sülfadiazin & SD300 & $(300 \mu \mathrm{g})$ & Oxoid \\
Nalidiksik Asit & NA30 & $(30 \mu \mathrm{g})$ & Oxoid \\
Enrofloksasin & ENR5 & $(5 \mu \mathrm{g})$ & Oxoid \\
Cefoperazone & CEP75 & $(75 \mu \mathrm{g})$ & Oxoid \\
Colistin & CT10 & $(10 \mu \mathrm{g})$ & Oxoid \\
Oksitetrasiklin & T30 & $(30 \mu \mathrm{g})$ & Oxoid \\
Norfloksasin & NOR10 & $(10 \mu \mathrm{g})$ & Oxoid \\
Ceftriaksone & CRO30 & $(30 \mu \mathrm{g})$ & Oxoid \\
Oksasilin & OX1 & $(1 \mu \mathrm{g})$ & Oxoid \\
Apramisin & APR15 & $(15 \mu \mathrm{g})$ & Oxoid \\
Siprofloksasin & CIP5 & $(5 \mu \mathrm{g})$ & Oxoid \\
Klindamisin & DA2 & $(2 \mu \mathrm{g})$ & Oxoid \\
Tylosin & TY15 & $(15 \mu \mathrm{g})$ & Oxoid \\
Flumequin & FLM30 & $(30 \mu \mathrm{g})$ & Oxoid \\
Sefalotin & KF30 & $(30 \mu \mathrm{g})$ & Oxoid \\
Pristinamisin & PT15 & $(15 \mu \mathrm{g})$ & Oxoid \\
Nitrofurantoin & F300 & $(300 \mu \mathrm{g})$ & Oxoid \\
Gentamisin & CN10 & $(10 \mu \mathrm{g})$ & Oxoid \\
Sülfametoksazol/Trimetoprim & SXT25 & $(25 \mu \mathrm{g})$ & Oxoid \\
Oksolinik Asit & OA2 & $(2 \mu \mathrm{g})$ & Oxoid \\
Kanamisin & K30 & $(30 \mu \mathrm{g})$ & Oxoid \\
Doksisiklin & DO30 & $(30 \mu \mathrm{g})$ & Oxoid \\
Kloramfenikol & C30 & $(30 \mu \mathrm{g})$ & Oxoid \\
Streptomisin & S10 & $(10 \mu \mathrm{g})$ & Oxoid \\
Ampisilin & AM10 & $(10 \mu \mathrm{g})$ & Oxoid \\
Eritromisin & E15 & $(15 \mu \mathrm{g})$ & Oxoid \\
Vankomisin & VA30 & $(30 \mu \mathrm{g})$ & Oxoid \\
Penisilin G & P10 & $(10 \mu \mathrm{g})$ & Oxoid \\
\hline \hline & & & \\
\hline & & & \\
\hline
\end{tabular}

\section{Kullanılan suşlar}

Çalışma da Bursa Uludağ Üniversitesi (BUÜ), Isparta Uygulamalı Bilimler Üniversitesi (ISUBÜ), Ondokuz Mayıs Üniversitesi'nden (OMÜ) hasta balıklardan izole edilmiş 20 A. hydrophila suşu ve A. hydrophila ATCC 7966 referans suşu kullanılmıştır (Tablo 2.) Suşlar çalışmada kullanılıncaya kadar $-80^{\circ} \mathrm{C}^{\prime}$ de depolanmıştır (Ausubel vd., 1988).

\section{A. hydrophila suşlarının üretim ve depolanması}

Deneylerde kullanılan her suş uzun süreli saklama amacıyla, \%20'lik gliserinli 2-3 ml TSB ortamında cryo tüplerde (3-6 ay), $-80^{\circ} \mathrm{C}^{\prime}$ de muhafaza edilmiştir. Depolanan bakteriler günlük kullanım için $-80^{\circ} \mathrm{C}$ 'den alınarak $-20^{\circ} \mathrm{C}$ 'de bekletildikten sonra aseptik şartlarda TSA besiyerlerine saf koloni olacak şekilde ekilmiştir. Ekimleri yapılan bakteriler $25^{\circ} \mathrm{C}$ 'de 24 saat süreyle inkübe edilmiştir. Daha sonra günlük kullanım amacıyla maximum 7 gün süreyle $+4^{\circ} \mathrm{C}^{\prime}$ de saklanmıştır. 
Tablo 2. Çalışmada kullanılan A. hydrophila suşları

\begin{tabular}{|c|c|c|c|}
\hline Sayı & Suş kodu & İzolasyon bölgesi & İzolasyon kaynağı \\
\hline Referans Suş & ATCC 7966 & Amerika Birleşik Devletleri & Konserve sütten \\
\hline 1. Suş & AH RSKK 05049 & Refik Saydam Ulusal Tıp Kültür Koleksiyonu (RSKK) & RSKK \\
\hline 2. Suş & AH SAHA & Karadeniz/Türkiye & Gökkuşağı Alabalığg \\
\hline 3. Suş & AH S & Akdeniz/Türkiye & Sazan Balığ 1 \\
\hline 4. Suş & AH J & Akdeniz/Türkiye & Japon Balığg \\
\hline 5. Suş & AH 2 & Karadeniz/Türkiye & Gökkuşağı Alabalığı \\
\hline 6. Suş & AH 3 & Ege/Türkiye & Gökkuşağı Alabalığ \\
\hline 7. Suş & $\mathrm{AH} 4$ & Karadeniz/Türkiye & Gökkuşağı Alabalığı \\
\hline 8. Suş & AH 12.1 & Karadeniz/Türkiye & Gökkuşağı Alabalığı \\
\hline 9. Suş & AH 14 & Karadeniz/Türkiye & Gökkuşağı Alabalığı \\
\hline 10. Suş & AH 15 & Karadeniz/Türkiye & Gökkuşağı Alabalığ \\
\hline 11. Suş & AH 16 & Karadeniz/Türkiye & Gökkuşağı Alabalığı \\
\hline 12. Suş & AH 108 & Ege/Türkiye & Gökkuşağı Alabalığ \\
\hline 13. Suş & AH 113 & İç Anadolu/Türkiye & Gökkuşağı Alabalığı \\
\hline 14. Suş & AH 216 & Ege/Türkiye & Kefal \\
\hline 15. Suş & AH 217 & Ege/Türkiye & Levrek \\
\hline 16. Suş & AH 219 & Ege/Türkiye & Tekir \\
\hline 17. Suş & AH 220 & Ege/Türkiye & Çipura \\
\hline 18. Suş & AH 222 & Ege/Türkiye & Kefal \\
\hline 19. Suş & AH 230 & Ege/Türkiye & Gökkuşağı Alabalığı \\
\hline 20. Suş & AH 232 & Ege/Türkiye & Gökkuşağı Alabalığı \\
\hline
\end{tabular}

AH: A. hydrophila

ATCC: American Type Culture Collection

RSKK: Refik Saydam Ulusal Tıp Kültür Koleksiyonu

\section{Yöntem}

\section{A. hydrophila suşların identifikasyon testleri}

Farklı hasta balıklardan izole edilmiş A. hydrophila suşları pasajlar yapılarak gençleştirilmiştir. Gençleştirme işleminde daha önceden izole edilerek identifikasyonları yapılan ve $-80^{\circ} \mathrm{C}$ 'de tutulan $A$. hydrophila suşları aseptik şartlarda TSA besiyerine ekilerek $25^{\circ} \mathrm{C}$ 'de inkübasyona bırakılmıştır. İnkübasyon sonucu gençleştirilen A. hydrophila suşlarının ve A. hydrophila ATCC 7966 referans suşunun saf koloni olacak şekilde Pseudomonas aeromonas selective agar base (Glutamate starch phenol red agarda: GSP Agarda) sarı pigmentli koloni oluşturması ayırıcı teşhisiyle tür tespiti yapılmıştır. Ayrıca Gram boyama testi, vibriostat testi, O/F testi, suşların hareketli olup olmadıklarının belirlenmesi amaciyla lam üzerinde mikroskopta incelemeyle hareketlilik testi, katalaz testi, sitokrom oksidaz testi ile fenotipik testleriyle A. hydrophila suşlarının testleri yapılarak tekrar doğrulanmıştır (Cappuccino ve Sherman, 1992; Lasee, 1995; Austin ve Austin, 2016).

\section{Kirby-Bauer disk difüzyon yöntemi antibiyogram testi}

Çalışmada kullanılan suşların antibiyotik duyarlılıkları Clinical Laboratory Standards Institute (CLSI) kriterler temel alınarak Mueller Hinton agarda Kirby-Bauer disk difüzyon yöntemiyle belirlenmiştir. Çalışmada A. hydrophila ATCC 7966 referans suşu ve A. hydrophila suşlarının antibiyotik direnç profilleri 28 çeşit antibiyotiğe karşı in vitro araştırılmışıtır. Testte Gram negatif bakterilerin tedavisinde en çok tercih edilen ve literatür taramasında en çok kullanılan Sülfadiazin (SD300, $300 \mu \mathrm{g}$ ), Nalidiksik Asit (NA30, $30 \mu \mathrm{g}$ ), Enrofloksasin (ENR5, $5 \mu \mathrm{g}$ ), Cefoperazone (CEP75, $75 \mu \mathrm{g}$ ), Colistin (CT10, $10 \mu \mathrm{g}$ ), Oksitetrasiklin (T30, $30 \mu \mathrm{g})$, Norfloksasin N(OR:10, $10 \mu \mathrm{g})$, Ceftriaksone (CRO30, $30 \mu \mathrm{g}$ ), Oksasilin (OX1, $1 \mu \mathrm{g}$ ), Apramisin (APR15, $15 \mu \mathrm{g}$ ), Siprofloksasin (CIP5, $5 \mu \mathrm{g}$ ), Klindamisin (DA2, $2 \mu \mathrm{g}$ ), Tylosin (TY15, $15 \mu \mathrm{g}$ ), Flumequin (FLM30, $30 \mu \mathrm{g}$ ), Sefalotin (KF30, $30 \mu \mathrm{g}$ ), Pristinamisin (PT15, $15 \mu \mathrm{g}$ ), Nitrofurantoin (F300, $300 \mu \mathrm{g}$ ), Gentamisin (CN10, 10 $\mu \mathrm{g}$ ), Sülfametoksazol/Trimetoprim (SXT25, $25 \mu \mathrm{g}$ ), Oksolinik Asit (OA2, $2 \mu \mathrm{g}$ ), Kanamisin (K30, 30 $\mu \mathrm{g}$ ), Doksisiklin (DO30, $30 \mu \mathrm{g}$ ), Kloramfenikol (C30, $30 \mu \mathrm{g}$ ), Streptomisin (S10, $10 \mu \mathrm{g}$ ), Ampisilin (AM10, $10 \mu \mathrm{g}$ ), Eritromisin (E15, $15 \mu \mathrm{g}$ ), Vankomisin (VA30, $30 \mu \mathrm{g}$ ), Penisilin G (P10, $10 \mu \mathrm{g}$ ) Oxoid marka antibiyotikleri kullanılmıştır. Mc Farland 0,5 (Biosan DEN-1) bulanıklığında hazırlanan bakteri süspansiyonundan Müller Hinton Agar (Merck) besiyerine 0,1 ml konularak besi yeri yüzeyine steril eküvyon çubuklar ile yayılması sağlanmıştır. Daha sonra petriler oda sıcaklığında 5-10 dakika bekletilmiştir. Agarın yüzeyine çeşitli konsantrasyonlarda farklı antibiyotikleri içeren diskler steril 
pens ile yerleştirilerek $25^{\circ} \mathrm{C}$ 'de $24-48$ saat inkübe edilmiştir. 24-48 saat süren inkübasyon sonunda diskler etrafında gelişen zonların çapları milimetrik olarak ölçülerek suşların duyarlı ve dirençli olup olmadıkları hassas (S), dirençli (R) ve orta derece de duyarlı (I) olarak CLSI, 2017 kriterlerine göre değerlendirilmiştir (Mueller ve Hinton, 1941; CLSI, 2017). Testler 3 tekrarlı olarak gerçekleştirilmiştir.

\section{Çoklu antibiyotik dirençliliği (ÇAD) indeksinin hesaplanması}

Çoklu antibiyotik dirençliliği (ÇAD) 'Multi Drug Resistant, MDR" indeksi test organizmalarının dirençli olduğu antibiyotik sayısının toplam kullanılan antibiyotik sayısına oranı ile hesaplanmıştır. Hesaplanan ÇAD indeksi sonucunda 0,2 'den daha büyük olan suşların çoklu antibiyotik dirençliliği olduğu belirlenmiştir (Krumperman, 1983; Paul vd., 1997; Ehinmidu, 2003; Matyar, 2016).

\section{BULGULAR}

\section{Kirby-Bauer disk difüzyon yöntemiyle antibiyogram testi sonuçları}

A. hydrophila suşlarının zon çaplarının mm bazında ölçülerek yapıldığı bu testte farklı suşların farklı antibiyotiklere karşı oluşturdukları direnç ve duyarlılıkları belirlenmiştir (Şekil 1. ve Tablo 3.).

Araştırma sonucunda 20 A. hydrophila suşunun ve A. hydrophila ATCC 7966 referans suşunun 28 farklı antibiyotik kullanılarak yapılan antibiyogram test sonuçları incelendiğinde, her bir suşun farklı düzeyde antibiyotik duyarlılıklarının olduğu tespit edilmiştir (Tablo 3.). A. hydrophila suşlarının 28 antibiyotiğin, 14'üne duyarlı olduğu 12'sine karşı dirençli olduğu ve 2'sine orta derecede duyarlı olduğu saptanmıştır.

Çalışmada A. hydrophila suşlarının oksasilin'e \%100, ampisilin'e \%100, vankomisin'e \%100, penisilin G'ye \%100, klindamisin'e \%95,23, tilosin'e \%95,23, oksitetrasiklin'e \%90,47, siprofloksasin'e \%90,47, pristinamisin'e \%90,47, sefalotin'e \%80,95, oksolinik asit'e \%80,95, nitrofurantoin'e \%61,90 oranında dirençli olduğu belirlenmiştir. Yine suşlarının norfloksasin'e \%100, gentamisin'e \%95,23, enrofloksasin'e \%95,23, flumekuin'e \%90,47, kloramfenikol'e \%90,47, kolistin'e \%80,95, streptomisin'e \%80,95, nalidiksik asit'e \%71,42, sulfametoksazol/trimetoprim'e $\% 71,42$, seftriakzon'a $\% 66,68$, sefoperazon'a $\% 52,38$, sülfadiazin'e $\% 47,61$, kanamisin'e $\% 47,61$, doksisiklin'e \%42,85 oranında duyarlı olduğu saptanmıştır. Ek olarak eritromisin'e \%76,19 ve apramisin'e \%57,14 oranında orta derecede duyarlı olduğu bulunmuştur. Çalışmada elde edilen antibiyotik duyarlılık yüzdeleri Tablo 4'de verilmiştir.

Çoklu antibiyotik direnci (ÇAD) indeksi sonuçlarına göre A. hydrophila suşlarının sülfadiazin, oksitetrasiklin, oksasilin, apramisin, klindamisin, tilosin, sefalotin, pristinamisin, nitrofurantoin, sulfametoksazol/trimetoprim, oksolinik asit, ampisilin, vankomisin ve penisilin G olmak üzere 14 farklı antibiyotiğe karşı çoklu antibiyotik direncinin olduğu belirlenmiştir (Tablo 4.). 
Tablo 3. A. hydrophila suşlarının antibiyogram sonuçları (CLSI, 2017)

\begin{tabular}{|c|c|c|c|c|c|c|c|c|c|c|c|c|c|c|c|c|c|c|c|c|c|}
\hline \multirow{2}{*}{ 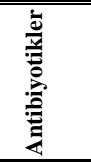 } & \multicolumn{21}{|c|}{ Sensitivity; R: Resistans, S: Susceptible I: Intermediate (Zon çapı: mm) Suşlar } \\
\hline & $\begin{array}{l}\text { ATCC } \\
7966 \\
\end{array}$ & $\begin{array}{c}\text { AH RSKK } \\
05049\end{array}$ & $\begin{array}{c}\text { AH } \\
\text { SAHA }\end{array}$ & $\begin{array}{c}\mathrm{AH} \\
\mathrm{S}\end{array}$ & $\begin{array}{c}\mathrm{AH} \\
\mathrm{J}\end{array}$ & $\begin{array}{c}\mathrm{AH} \\
2 \\
\end{array}$ & $\begin{array}{c}\mathrm{AH} \\
3 \\
\end{array}$ & $\begin{array}{c}\mathrm{AH} \\
4 \\
\end{array}$ & $\begin{array}{c}\mathrm{AH} \\
12.1 \\
\end{array}$ & $\begin{array}{c}\mathrm{AH} \\
14 \\
\end{array}$ & $\begin{array}{c}\mathrm{AH} \\
15 \\
\end{array}$ & $\begin{array}{l}\mathrm{AH} \\
16 \\
\end{array}$ & $\begin{array}{l}\mathrm{AH} \\
108 \\
\end{array}$ & $\begin{array}{l}\mathrm{AH} \\
113 \\
\end{array}$ & $\begin{array}{l}\mathrm{AH} \\
216 \\
\end{array}$ & $\begin{array}{l}\mathrm{AH} \\
217 \\
\end{array}$ & $\begin{array}{l}\mathrm{AH} \\
219 \\
\end{array}$ & $\begin{array}{l}\mathrm{AH} \\
220 \\
\end{array}$ & $\begin{array}{l}\mathrm{AH} \\
222 \\
\end{array}$ & $\begin{array}{l}\mathrm{AH} \\
230 \\
\end{array}$ & $\begin{array}{l}\mathrm{AH} \\
232 \\
\end{array}$ \\
\hline SD300 & $\mathrm{S}(19)$ & $\mathrm{R}(0)$ & $\mathrm{S}(20)$ & $\mathrm{R}(0)$ & $\mathrm{S}(2)$ & $\mathrm{S}(16)$ & $\mathrm{S}(20)$ & $\mathrm{S}(23)$ & $\mathrm{S}(18)$ & $\mathrm{I}(14)$ & $\mathrm{R}(10)$ & $\mathrm{R}(0)$ & $\mathrm{S}(20)$ & $\mathrm{S}(22)$ & $\mathrm{R}(0)$ & $\mathrm{R}(0)$ & $\mathrm{R}(0)$ & $\mathrm{R}(0)$ & $\mathrm{S}(18)$ & $\mathrm{R}(0)$ & $\mathrm{I}(13)$ \\
\hline NA30 & $\mathrm{S}(26)$ & $\mathrm{R}(0)$ & $\mathrm{S}(34)$ & $\mathrm{S}(30)$ & $\mathrm{S}(25)$ & $\mathrm{S}(27)$ & $\mathrm{S}(27)$ & $\mathrm{S}(26)$ & $\mathrm{S}(25)$ & $\mathrm{R}(0)$ & $\mathrm{S}(23)$ & $\mathrm{R}(0)$ & $\mathrm{S}(25)$ & $\mathrm{I}(18)$ & $S(27)$ & $\mathrm{S}(22)$ & $\mathrm{S}(24)$ & $\mathrm{S}(21)$ & $\mathrm{S}(25)$ & $\mathrm{R}(0)$ & $\mathrm{R}(0)$ \\
\hline ENR5 & $\mathrm{S}(30)$ & $\mathrm{S}(28)$ & $\mathrm{S}(40)$ & $\mathrm{S}(34)$ & $\mathrm{S}(40)$ & $\mathrm{S}(31)$ & $\mathrm{S}(30)$ & $\mathrm{S}(30)$ & $\mathrm{R}(10)$ & $\mathrm{S}(25)$ & $\mathrm{S}(34)$ & $\mathrm{S}(35)$ & $\mathrm{S}(31)$ & $\mathrm{S}(26)$ & $\mathrm{S}(31)$ & $\mathrm{S}(34)$ & $\mathrm{S}(35)$ & $\mathrm{S}(34)$ & $\mathrm{S}(40)$ & $\mathrm{S}(33)$ & S(27) \\
\hline CEP75 & $\mathrm{I}(20)$ & I $(19)$ & $\mathrm{S}(30)$ & $\mathrm{I}(20)$ & $\mathrm{S}(24)$ & $\mathrm{I}(20)$ & $\mathrm{I}(20)$ & $\mathrm{S}(22)$ & $\mathrm{S}(26)$ & $\mathrm{S}(29)$ & $\mathrm{S}(25)$ & $\mathrm{I}(20)$ & $\mathrm{I}(20)$ & $\mathrm{S}(30)$ & $\mathrm{I}(20)$ & $\mathrm{S}(27)$ & $\mathrm{S}(26)$ & $\mathrm{R}(14)$ & $\mathrm{S}(21)$ & $\mathrm{S}(22)$ & $\mathrm{I}(20)$ \\
\hline CT10 & $\mathrm{S}(12)$ & $\mathrm{R}(10)$ & $\mathrm{S}(13)$ & $\mathrm{S}(12)$ & $\mathrm{S}(12)$ & $\mathrm{S}(13)$ & $\mathrm{S}(12)$ & $\mathrm{S}(13)$ & $\mathrm{S}(14)$ & $\mathrm{S}(12)$ & $\mathrm{R}(0)$ & $\mathrm{S}(12)$ & $\mathrm{S}(11)$ & $\mathrm{S}(13)$ & $\mathrm{S}(20)$ & $\mathrm{S}(19)$ & $\mathrm{R}(0)$ & $\mathrm{S}(15)$ & $\mathrm{S}(11)$ & $\mathrm{R}(0)$ & $\mathrm{S}(13)$ \\
\hline T30 & $\mathrm{R}(0)$ & $\mathrm{R}(20)$ & $\mathrm{I}(23)$ & $\mathrm{R}(0)$ & $\mathrm{R}(20)$ & $\mathrm{R}(0)$ & $\mathrm{R}(0)$ & $\mathrm{R}(0)$ & $\mathrm{R}(0)$ & $\mathrm{I}(22)$ & $\mathrm{R}(9)$ & $\mathrm{R}(0)$ & $\mathrm{R}(0)$ & $\mathrm{R}(0)$ & $\mathrm{R}(0)$ & $\mathrm{R}(0)$ & $\mathrm{R}(21)$ & $\mathrm{R}(0)$ & $\mathrm{R}(0)$ & $\mathrm{R}(16)$ & $\mathrm{R}(0)$ \\
\hline NOR10 & $\mathrm{S}(33)$ & S(33) & $\mathrm{S}(41)$ & $\mathrm{S}(33)$ & $\mathrm{S}(35)$ & $\mathrm{S}(32)$ & $\mathrm{S}(31)$ & $\mathrm{S}(32)$ & $\mathrm{S}(28)$ & $\mathrm{S}(23)$ & $\mathrm{S}(19)$ & $\mathrm{S}(32)$ & $\mathrm{S}(30)$ & $\mathrm{S}(20)$ & $\mathrm{S}(27)$ & $\mathrm{S}(34)$ & S(24) & $\mathrm{S}(26)$ & $\mathrm{S}(29)$ & $\mathrm{S}(24)$ & $\mathrm{S}(30)$ \\
\hline CRO30 & $\mathrm{S}(25)$ & $\mathrm{S}(42)$ & $\mathrm{S}(33)$ & $S(24)$ & $\mathrm{S}(24)$ & $\mathrm{S}(26)$ & $\mathrm{S}(25)$ & $S(26)$ & $\mathrm{R}(16)$ & $\mathrm{S}(31)$ & $\mathrm{I}(22)$ & $\mathrm{S}(28)$ & $\mathrm{S}(25)$ & $\mathrm{R}(18)$ & $\mathrm{I}(21)$ & $\mathrm{S}(30)$ & $\mathrm{R}(16)$ & $\mathrm{R}(15)$ & $\mathrm{S}(26)$ & $\mathrm{R}(9)$ & $\mathrm{S}(25)$ \\
\hline OX1 & $\mathrm{R}(0)$ & $\mathrm{R}(0)$ & $\mathrm{R}(0)$ & $\mathrm{R}(0)$ & $\mathrm{R}(0)$ & $\mathrm{R}(0)$ & $\mathrm{R}(0)$ & $\mathrm{R}(0)$ & $\mathrm{R}(0)$ & $\mathrm{R}(0)$ & $\mathrm{R}(9)$ & $\mathrm{R}(0)$ & $\mathrm{R}(0)$ & $\mathrm{R}(0)$ & $\mathrm{R}(0)$ & $\mathrm{R}(0)$ & $\mathrm{R}(0)$ & $\mathrm{R}(0)$ & $\mathrm{R}(0)$ & $\mathrm{R}(0)$ & $\mathrm{R}(0)$ \\
\hline APR15 & $\mathrm{I}(15)$ & I(15) & $\mathrm{I}(15)$ & $\mathrm{I}(15)$ & $\mathrm{R}(13)$ & $\mathrm{I}(14)$ & $\mathrm{I}(15)$ & $\mathrm{I}(15)$ & $\mathrm{S}(18)$ & $\mathrm{I}(15)$ & $\mathrm{R}(12)$ & $\mathrm{I}(15)$ & $\mathrm{I}(15)$ & $\mathrm{R}(11)$ & $\mathrm{R}(13)$ & $\mathrm{I}(16)$ & $\mathrm{S}(18)$ & $\mathrm{R}(12)$ & $\mathrm{R}(13)$ & $\mathrm{R}(13)$ & $\mathrm{I}(16)$ \\
\hline CIP5 & $\mathrm{S}(35)$ & $\mathrm{S}(28)$ & $\mathrm{S}(42)$ & $\mathrm{S}(35)$ & $\mathrm{S}(38)$ & $\mathrm{S}(37)$ & $\mathrm{S}(37)$ & $\mathrm{S}(35)$ & $\mathrm{S}(34)$ & $\mathrm{S}(26)$ & $\mathrm{S}(33)$ & $\mathrm{S}(35)$ & $\mathrm{S}(36)$ & $\mathrm{S}(30)$ & $\mathrm{S}(33)$ & $\mathrm{R}(0)$ & $\mathrm{S}(37)$ & $\mathrm{I}(20)$ & $\mathrm{S}(38)$ & $\mathrm{S}(26)$ & $\mathrm{S}(29)$ \\
\hline DA2 & $\mathrm{R}(0)$ & $\mathrm{R}(0)$ & $\mathrm{R}(0)$ & $\mathrm{R}(0)$ & $\mathrm{R}(0)$ & $\mathrm{R}(0)$ & $\mathrm{R}(0)$ & $\mathrm{R}(0)$ & $\mathrm{R}(0)$ & $\mathrm{R}(0)$ & $\mathrm{R}(9)$ & $\mathrm{R}(8)$ & $\mathrm{R}(0)$ & $\mathrm{R}(0)$ & $\mathrm{R}(0)$ & $\mathrm{R}(0)$ & $\mathrm{R}(9)$ & $\mathrm{R}(0)$ & $\mathrm{R}(0)$ & $\mathrm{S}(22)$ & $\mathrm{R}(0)$ \\
\hline TY15 & $\mathrm{R}(0)$ & $\mathrm{R}(0)$ & $\mathrm{R}(0)$ & $\mathrm{R}(0)$ & $\mathrm{R}(0)$ & $\mathrm{R}(0)$ & $\mathrm{R}(0)$ & $\mathrm{R}(0)$ & $\mathrm{R}(0)$ & $\mathrm{R}(0)$ & $\mathrm{R}(0)$ & $\mathrm{R}(0)$ & $\mathrm{R}(0)$ & $\mathrm{R}(0)$ & $\mathrm{R}(0)$ & $\mathrm{R}(0)$ & $\mathrm{R}(0)$ & $\mathrm{R}(0)$ & $\mathrm{R}(0)$ & $\mathrm{S}(21)$ & $\mathrm{R}(0)$ \\
\hline FLM30 & $\mathrm{S}(34)$ & $\mathrm{S}(43)$ & $\mathrm{S}(36)$ & $\mathrm{S}(35)$ & $\mathrm{S}(34)$ & $\mathrm{S}(33)$ & $\mathrm{S}(34)$ & $\mathrm{S}(34)$ & $\mathrm{S}(32)$ & $\mathrm{R}(11)$ & $\mathrm{S}(31)$ & $\mathrm{S}(34)$ & $\mathrm{S}(25)$ & $\mathrm{S}(36)$ & $\mathrm{S}(35)$ & $\mathrm{S}(29)$ & $\mathrm{S}(31)$ & $\mathrm{S}(27)$ & $\mathrm{S}(35)$ & $\mathrm{S}(27)$ & $\mathrm{I}(22)$ \\
\hline KF30 & $\mathrm{R}(0)$ & $\mathrm{R}(0)$ & $\mathrm{R}(0)$ & $\mathrm{R}(0)$ & $\mathrm{S}(20)$ & $\mathrm{R}(0)$ & $\mathrm{R}(0)$ & $\mathrm{R}(0)$ & $\mathrm{R}(0)$ & $\mathrm{R}(0)$ & $\mathrm{R}(8)$ & $\mathrm{R}(0)$ & $\mathrm{R}(0)$ & $\mathrm{R}(10)$ & $S(23)$ & $\mathrm{S}(22)$ & $\mathrm{R}(0)$ & $\mathrm{S}(22)$ & $\mathrm{R}(0)$ & $\mathrm{R}(7)$ & $\mathrm{R}(0)$ \\
\hline PT15 & $\mathrm{R}(0)$ & $\mathrm{R}(0)$ & $\mathrm{R}(0)$ & $\mathrm{R}(0)$ & $\mathrm{R}(0)$ & $\mathrm{R}(0)$ & $\mathrm{R}(0)$ & $\mathrm{R}(0)$ & $\mathrm{R}(0)$ & $\mathrm{R}(11)$ & $R(10)$ & $\mathrm{R}(0)$ & $\mathrm{R}(0)$ & $\mathrm{R}(10)$ & $\mathrm{R}(0)$ & $\mathrm{R}(0)$ & $\mathrm{S}(25)$ & $\mathrm{R}(10)$ & $\mathrm{R}(0)$ & $\mathrm{S}(25)$ & $R(11)$ \\
\hline F300 & $\mathrm{R}(0)$ & $\mathrm{R}(13)$ & $S(26)$ & $\mathrm{R}(0)$ & $\mathrm{S}(21)$ & $\mathrm{R}(0)$ & $\mathrm{R}(0)$ & $\mathrm{R}(0)$ & $\mathrm{R}(0)$ & $\mathrm{S}(20)$ & $\mathrm{R}(0)$ & $\mathrm{R}(0)$ & $\mathrm{R}(0)$ & $\mathrm{R}(0)$ & $\mathrm{R}(0)$ & $\mathrm{S}(20)$ & $\mathrm{S}(17)$ & $\mathrm{I}(15)$ & $\mathrm{R}(0)$ & $S(19)$ & $\mathrm{S}(23)$ \\
\hline CN10 & $\mathrm{S}(20)$ & $\mathrm{R}(11)$ & $\mathrm{S}(20)$ & $S(20)$ & $\mathrm{S}(20)$ & $\mathrm{S}(21)$ & $\mathrm{S}(20)$ & $\mathrm{S}(21)$ & $\mathrm{S}(24)$ & $\mathrm{S}(20)$ & $\mathrm{S}(21)$ & $\mathrm{S}(20)$ & $\mathrm{S}(21)$ & $\mathrm{S}(15)$ & $\mathrm{S}(18)$ & $\mathrm{S}(21)$ & S(24) & $\mathrm{S}(23)$ & $\mathrm{S}(21)$ & $\mathrm{S}(21)$ & $\mathrm{S}(22)$ \\
\hline SXT25 & $\mathrm{S}(25)$ & $\mathrm{R}(0)$ & $\mathrm{S}(29)$ & $\mathrm{R}(0)$ & $\mathrm{S}(25)$ & $\mathrm{S}(27)$ & $\mathrm{S}(24)$ & $\mathrm{S}(26)$ & $\mathrm{S}(23)$ & $S(16)$ & $\mathrm{S}(26)$ & $\mathrm{S}(25)$ & $\mathrm{S}(24)$ & $\mathrm{S}(27)$ & $\mathrm{S}(26)$ & $\mathrm{R}(0)$ & $\mathrm{R}(0)$ & $\mathrm{R}(0)$ & $\mathrm{S}(27)$ & $\mathrm{R}(0)$ & $\mathrm{S}(21)$ \\
\hline $\mathrm{OA} 2$ & $\mathrm{R}(0)$ & $\mathrm{R}(0)$ & $\mathrm{I}(26)$ & $\mathrm{R}(0)$ & $\mathrm{I}(27)$ & $\mathrm{R}(0)$ & $\mathrm{R}(0)$ & $\mathrm{R}(0)$ & $\mathrm{R}(0)$ & $\mathrm{R}(0)$ & $\mathrm{R}(18)$ & $\mathrm{R}(0)$ & $\mathrm{R}(0)$ & $\mathrm{I}(25)$ & $\mathrm{R}(17)$ & $\mathrm{R}(20)$ & $\mathrm{R}(20)$ & $\mathrm{I}(26)$ & $\mathrm{R}(0)$ & $\mathrm{R}(22)$ & $\mathrm{R}(0)$ \\
\hline K30 & $\mathrm{S}(18)$ & $\mathrm{S}(19)$ & S18) & $\mathrm{S}(18)$ & $\mathrm{I}(16)$ & $\mathrm{I}(17)$ & $\mathrm{I}(17)$ & $\mathrm{S}(18)$ & $\mathrm{S}(19)$ & $\mathrm{S}(18)$ & $\mathrm{S}(20)$ & $\mathrm{S}(18)$ & $\mathrm{I}(14)$ & $\mathrm{R}(0)$ & $\mathrm{R}(0)$ & $\mathrm{I}(14)$ & $\mathrm{I}(17)$ & $\mathrm{R}(0)$ & $\mathrm{S}(21)$ & $\mathrm{I}(14)$ & $\mathrm{I}(17)$ \\
\hline DO30 & $\mathrm{I}(11)$ & $S(24)$ & $\mathrm{S}(24)$ & $S(24)$ & $\mathrm{S}(18)$ & $\mathrm{R}(10)$ & $\mathrm{I}(12)$ & $\mathrm{I}(11)$ & $\mathrm{S}(22)$ & $\mathrm{S}(25)$ & $\mathrm{S}(16)$ & $\mathrm{I}(12)$ & $\mathrm{R}(9)$ & $\mathrm{R}(0)$ & $\mathrm{I}(12)$ & $\mathrm{I}(13)$ & $\mathrm{S}(28)$ & $\mathrm{I}(13)$ & $\mathrm{R}(10)$ & $\mathrm{S}(23)$ & $\mathrm{R}(10)$ \\
\hline $\mathrm{C} 30$ & $\mathrm{~S}(35)$ & $\mathrm{S}(36)$ & $\mathrm{S}(37)$ & $S(36)$ & $\mathrm{S}(32)$ & $\mathrm{S}(35)$ & $\mathrm{S}(35)$ & $\mathrm{S}(36)$ & $\mathrm{S}(34)$ & $\mathrm{S}(32)$ & $\mathrm{I}(16)$ & $\mathrm{S}(35)$ & $\mathrm{S}(33)$ & $\mathrm{S}(18)$ & $\mathrm{S}(28)$ & $\mathrm{S}(24)$ & $\mathrm{S}(34)$ & $\mathrm{S}(22)$ & $\mathrm{S}(39)$ & $\mathrm{S}(30)$ & $\mathrm{R}(11)$ \\
\hline $\mathrm{S} 10$ & $\mathrm{~S}(20)$ & $\mathrm{S}(21)$ & $\mathrm{S}(22)$ & $\mathrm{S}(20)$ & $\mathrm{S}(22)$ & $\mathrm{S}(20)$ & $\mathrm{S}(20)$ & $\mathrm{S}(20)$ & $\mathrm{S}(29)$ & $\mathrm{S}(20)$ & $\mathrm{S}(25)$ & $\mathrm{S}(20)$ & $\mathrm{S}(21)$ & $\mathrm{S}(18)$ & $\mathrm{R}(10)$ & $\mathrm{I}(14)$ & $\mathrm{S}(28)$ & $\mathrm{I}(12)$ & $\mathrm{S}(21)$ & $\mathrm{S}(16)$ & $\mathrm{R}(0)$ \\
\hline AM10 & $\mathrm{R}(0)$ & $\mathrm{R}(0)$ & $\mathrm{R}(0)$ & $\mathrm{R}(0)$ & $\mathrm{R}(0)$ & $\mathrm{R}(0)$ & $\mathrm{R}(0)$ & $\mathrm{R}(0)$ & $\mathrm{R}(0)$ & $\mathrm{R}(0)$ & $\mathrm{R}(9)$ & $\mathrm{R}(0)$ & $\mathrm{R}(0)$ & $\mathrm{R}(0)$ & $\mathrm{R}(0)$ & $\mathrm{R}(0)$ & $\mathrm{R}(9)$ & $\mathrm{R}(0)$ & $\mathrm{R}(0)$ & $\mathrm{R}(0)$ & $\mathrm{R}(0)$ \\
\hline E15 & $\mathrm{I}(15)$ & I(15) & $\mathrm{I}(20)$ & $\mathrm{I}(14)$ & $\mathrm{I}(17)$ & I(16) & $\mathrm{I}(15)$ & $\mathrm{I}(15)$ & $\mathrm{I}(22)$ & $\mathrm{I}(13)$ & $\mathrm{I}(19)$ & $\mathrm{I}(14)$ & $\mathrm{I}(14)$ & $\mathrm{R}(0)$ & $\mathrm{R}(0)$ & $\mathrm{R}(0)$ & $\mathrm{I}(21)$ & $\mathrm{R}(0)$ & $\mathrm{I}(17)$ & $\mathrm{S}(31)$ & $\mathrm{I}(22)$ \\
\hline VA30 & $\mathrm{R}(0)$ & $\mathrm{R}(0)$ & $\mathrm{R}(0)$ & $\mathrm{R}(0)$ & $\mathrm{R}(0)$ & $\mathrm{R}(0)$ & $\mathrm{R}(0)$ & $\mathrm{R}(0)$ & $\mathrm{R}(0)$ & $\mathrm{R}(0)$ & $\mathrm{R}(0)$ & $\mathrm{R}(0)$ & $\mathrm{R}(0)$ & $\mathrm{R}(0)$ & $\mathrm{R}(0)$ & $\mathrm{R}(0)$ & $\mathrm{R}(0)$ & $\mathrm{R}(0)$ & $\mathrm{R}(0)$ & $\mathrm{R}(0)$ & $\mathrm{R}(0)$ \\
\hline P10 & $\mathrm{R}(0)$ & $\mathrm{R}(0)$ & $\mathrm{R}(0)$ & $\mathrm{R}(0)$ & $\mathrm{R}(0)$ & $\mathrm{R}(0)$ & $\mathrm{R}(0)$ & $\mathrm{R}(0)$ & $\mathrm{R}(0)$ & $\mathrm{R}(0)$ & $\mathrm{R}(0)$ & $\mathrm{R}(0)$ & $\mathrm{R}(0)$ & $\mathrm{R}(0)$ & $\mathrm{R}(0)$ & $\mathrm{R}(0)$ & $\mathrm{R}(0)$ & $\mathrm{R}(0)$ & $\mathrm{R}(0)$ & $\mathrm{R}(0)$ & $\mathrm{R}(0)$ \\
\hline
\end{tabular}

CLSI: The Clinical \& Laboratory Standards Institute

R: Resistant: Dirençli, I: Intermediate: Orta duyarlı, S: Susceptible: Duyarlı

SD300: Sulfadiazine, NA30: Nalidixic Acid, ENR5: Enrofloxacin, CEP75: Cefoperazone, CT10: Colistin, T30: Oxytetracycline, NOR:10 Norfloxacin, CRO30: Ceftriaxone, OX1: Oxacillin, APR15: Apramycin, CIP5:

Ciprofloxacin, DA2: Clindamycin, TY15: Tylosin, FLM30: Flumequine, KF30: Cephalothin, PT15: Pristinamycin, F300: Nitrofurantoin, CN10: Gentamicin, SXT25: Sulphamethoxazole/Trimethoprim, OA2: Oxolinic

Acid, K30: Kanamycin, DO30: Doxycycline, C30: Chloramphenicol, S10: Streptomycin, AM10: Ampicillin, E15: Erythromycin, VA30: Vancomycin, P10: Penicillin G 
Tablo 4. Antibiyotik duyarlılık yüzdeleri ve çoklu antibiyotik direnci (ÇAD) indeksi sonuçları

\begin{tabular}{|c|c|c|c|c|c|c|c|c|}
\hline Antibiyotik & $\begin{array}{c}\text { Antibiyotik } \\
\text { Dozu }\end{array}$ & $\begin{array}{c}\text { Dirençli } \\
\text { Suş Sayısı }\end{array}$ & $\begin{array}{c}\text { Dirençli } \\
\text { n }(\%)\end{array}$ & $\begin{array}{c}\text { Orta Duyarlı } \\
\text { Suş Sayısı }\end{array}$ & $\begin{array}{c}\text { Orta Duyarlı } \\
\text { n (\%) }\end{array}$ & $\begin{array}{c}\text { Duyarlı Suş } \\
\text { Sayısı }\end{array}$ & $\begin{array}{c}\text { Duyarlı } \\
\text { n (\%) }\end{array}$ & $\begin{array}{c}\text { ÇAD } \\
\text { İndeksi }\end{array}$ \\
\hline SD300 & $(300 \mu \mathrm{g})$ & 9 & $\% 42,85$ & 2 & $\% 9,52$ & 10 & $\% 47,61$ & 0,32 \\
\hline NA30 & $(30 \mu \mathrm{g})$ & 5 & $\% 23,80$ & 1 & $\% 4,76$ & 15 & $\% 71,42$ & 0,17 \\
\hline ENR5 & $(5 \mu \mathrm{g})$ & 1 & $\% 4,76$ & 0 & $\% 0$ & 20 & $\% 95,23$ & 0,03 \\
\hline CEP75 & $(75 \mu \mathrm{g})$ & 1 & $\% 4,76$ & 9 & $\% 42,85$ & 11 & $\% 52,38$ & 0,03 \\
\hline CT10 & $(10 \mu \mathrm{g})$ & 4 & $\% 19,04$ & 0 & $\% 0$ & 17 & $\% 80,95$ & 0,14 \\
\hline $\mathrm{T} 30$ & $(30 \mu \mathrm{g})$ & 19 & $\% 90,47$ & 2 & $\% 9,52$ & 0 & $\% 0$ & 0,67 \\
\hline NOR10 & $(10 \mu \mathrm{g})$ & 0 & $\% 0$ & 0 & $\% 0$ & 21 & $\% 100$ & 0 \\
\hline CRO30 & $(30 \mu \mathrm{g})$ & 5 & $\% 23,80$ & 2 & $\% 9,52$ & 14 & $\% 66,68$ & 0,17 \\
\hline OX1 & $(1 \mu \mathrm{g})$ & 21 & $\% 100,00$ & 0 & $\% 0$ & 0 & $\% 0$ & 0,75 \\
\hline APR15 & $(15 \mu \mathrm{g})$ & 7 & $\% 33,33$ & 12 & $\% 57,14$ & 2 & $\% 9,52$ & 0,25 \\
\hline CIP5 & $(5 \mu \mathrm{g})$ & 1 & $\% 4,76$ & 1 & $\% 4,76$ & 19 & $\% 90,47$ & 0,03 \\
\hline DA2 & $(2 \mu \mathrm{g})$ & 20 & $\% 95,23$ & 0 & $\% 0$ & 1 & $\% 4,76$ & 0,71 \\
\hline TY15 & $(15 \mu \mathrm{g})$ & 20 & $\% 95,23$ & 0 & $\% 0$ & 1 & $\% 4,76$ & 0,71 \\
\hline FLM30 & $(30 \mu \mathrm{g})$ & 1 & $\% 4,76$ & 1 & $\% 4,76$ & 19 & $\% 90,47$ & 0,03 \\
\hline KF30 & $(30 \mu \mathrm{g})$ & 17 & $\% 80,95$ & 0 & $\% 0$ & 4 & $\% 19,04$ & 0,60 \\
\hline PT15 & $(15 \mu \mathrm{g})$ & 19 & $\% 90,47$ & 0 & $\% 0$ & 2 & $\% 9,52$ & 0,67 \\
\hline F300 & $(300 \mu \mathrm{g})$ & 13 & $\% 61,90$ & 1 & $\% 4,76$ & 7 & $\% 33,33$ & 0,46 \\
\hline CN10 & $(10 \mu \mathrm{g})$ & 1 & $\% 4,76$ & 0 & $\% 0$ & 20 & $\% 95,23$ & 0,03 \\
\hline SXT25 & $(25 \mu \mathrm{g})$ & 6 & $\% 28,57$ & 0 & $\% 0$ & 15 & $\% 71,42$ & 0,21 \\
\hline $\mathrm{OA} 2$ & $(2 \mu \mathrm{g})$ & 17 & $\% 80,95$ & 4 & $\% 19,04$ & 0 & $\% 0$ & 0,60 \\
\hline K30 & $(30 \mu \mathrm{g})$ & 3 & $\% 14,28$ & 8 & $\% 38,09$ & 10 & $\% 47,61$ & 0,10 \\
\hline DO30 & $(30 \mu \mathrm{g})$ & 5 & $\% 23,80$ & 7 & $\% 33,33$ & 9 & $\% 42,85$ & 0,17 \\
\hline $\mathrm{C} 30$ & $(30 \mu \mathrm{g})$ & 1 & $\% 4,76$ & 1 & $\% 4,76$ & 19 & $\% 90,47$ & 0,03 \\
\hline $\mathrm{S} 10$ & $(10 \mu \mathrm{g})$ & 2 & $\% 9,52$ & 2 & $\% 9,52$ & 17 & $\% 80,95$ & 0,07 \\
\hline AM10 & $(10 \mu \mathrm{g})$ & 21 & $\% 100,00$ & 0 & $\% 0$ & 0 & $\% 0$ & 0,75 \\
\hline E15 & $(15 \mu \mathrm{g})$ & 4 & $\% 19,04$ & 16 & $\% 76,19$ & 1 & $\% 4,76$ & 0,14 \\
\hline VA30 & $(30 \mu \mathrm{g})$ & 21 & $\% 100,00$ & 0 & $\% 0$ & 0 & $\% 0$ & 0,75 \\
\hline $\mathrm{P} 10$ & $(10 \mu \mathrm{g})$ & 21 & $\% 100,00$ & 0 & $\% 0$ & 0 & $\% 0$ & 0,75 \\
\hline
\end{tabular}

R: Resistant: Dirençli, I: Intermediate: Orta duyarlı, S: Susceptible: Duyarlı

ÇAD: Çoklu antibiyotik direnci indeksi

SD300: Sulfadiazine, NA30: Nalidixic Acid, ENR5: Enrofloxacin, CEP75: Cefoperazone, CT10: Colistin, T30: Oxytetracycline, NOR:10 Norfloxacin, CRO30: Ceftriaxone, OX1: Oxacillin, APR15: Apramycin, CIP5: Ciprofloxacin, DA2: Clindamycin, TY15: Tylosin, FLM30: Flumequine, KF30: Cephalothin, PT15: Pristinamycin, F300: Nitrofurantoin, CN10: Gentamicin, SXT25: Sulphamethoxazole/Trimethoprim, OA2: Oxolinic Acid, K30: Kanamycin, DO30: Doxycycline, C30: Chloramphenicol, S10: Streptomycin, AM10: Ampicillin, E15: Erythromycin, VA30: Vancomycin, P10: Penicillin G
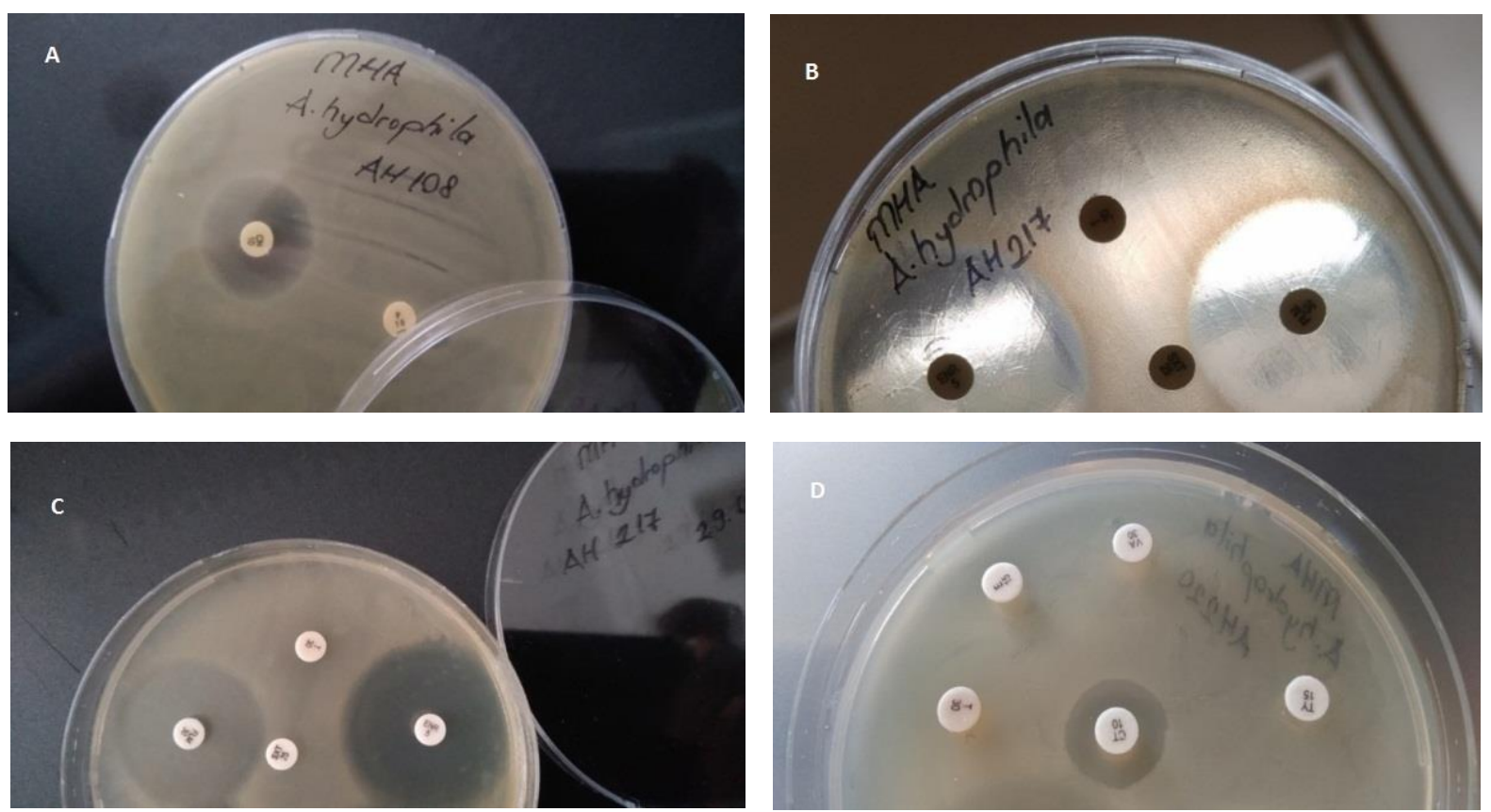

Şekil 1. A. A. hydrophila AH108 suşunun gentamisin duyarlılığı penisilin direnci, B.ve C. A. hydrophila AH217 suşunun enrofloksasin, flumekuin duyarlılı̆̆ oksitetrasiklin, sulfametoksazol/trimetoprim direnci, D. A. hydrophila AH220 suşunun sadece kolistin duyarlılı̆̆ tilosin, vankomisin, eritromisin, Kloramfenikol direnci 


\section{TARTIŞMA ve SONUÇ}

Bakteriyel direnç her açıdan tehdittir. Son zamanlarda dünya çapında antibiyotiklere dirençli, hatta çoklu dirençli, patojenik bakterilerde bir artış söz konusudur. Su ürünleri yetiştiriciliği yönetiminde profilaktif amaçla probiyotik uygulamaları (Gatesoupe, 1999; Verschuere vd., 2000), immunostimulantlar (Sakai, 1999) ve aş1lar (Gudding vd., 1999; Heppell ve Davis, 2000) başarılı bir şekilde kullanılmaktadır. Ancak tedavi sürecinde kullanılan antibiyotiklere karşı gittikçe gelişen direnç hastalıkların kontrol altına alınmasında yeni metotlara olan ihtiyacı arttırmıştır.

Birçok antibiyotiğe karşı gerek intrinsik, gerekse kazanılmış direnç göstererek tedaviyi zorlayan bir bakterinin antibiyotiklere direnci diğer bakterilere kolaylıkla transfer eden ve intestinal florada asemptomatik persistent kolonizasyon gösteren bu bakterilerin hastalıklardaki önemi giderek artmaktadır (Uttley vd., 1988).

Aeromonasların, penisilin G, ampisilin, karbenisilin, tikarsilin, streptomisin, sefalotin ve 1 . ve 2 . kuşak sefalosporinlerin çoğuna karşı dirençli olduğu; çoğu aminoglikozide, azlosilin, piperasilin kloramfenikol, tetrasiklin, sulfametoksazol/trimetoprim, kinolonlar ve 3. kuşak sefalosporinlere duyarlı oldukları belirtilmektedir. Bununla beraber her gün bu ilaçlara karşı direnç gelişmektedir. Yapılan çalışmalarla Aeromonas cinsinde çoklu direnç gelişimine neden olan R plazmidlerin varlığı saptanmıştır (Altwegg ve Jöhl, 1989). Bu çalışmada A. hydrophila'nın gün geçtikçe duyarlı olduğu ve tedavide önerilen başta oksitetrasiklin olmak üzere 12 antibiyotiğe karşı artık direnç kazandığ1 belirlenerek Altwegg ve Jöhl (1989) ile benzer sonuç vermiştir.

Sarkodie vd. (2019) 15 klinik A. hydrophila suşu 12 antibiyotik sınıfı olmak üzere 25 farklı antibiyotiğe karşı antibiyotik hassasiyetleri açısından incelenmiş ve neredeyse birçok antibiyotiğe karşı direnç geliştirdiğini bulumuşlardır. Suşların aminoglikozid sınıfına karşı \% 97,7 duyarlılık, $\beta$ laktam'a \%96,7 yüksek direnç, \%60,0 polipeptide orta direnç gösterdiğini bildirmişlerdir. Hatta $A$. hydrophila hastalıklarının tedavisinde penisilinden ve tetrasiklinden kaçınılması gerektiğini savunmuşlardır. Çalışmamızda da benzer durum söz konusu olup A. hydrophila suşlarının nerdeyse yarısının çalışmada kullanılan tüm antibiyotiklere direnç geliştirdiği görülmüştür ve penisilin $G$ (\%100) ve oksitetrasiklin'e $(\% 90,47)$ karşı görülen yüksek düzeydeki direnç Sarkodie vd. (2019) bulgularını desteklemektedir.

Hossain vd. (2019) tarafından zebra balığı kaynaklı 43 Aeromonas spp. (26 A. veronii biovar veronii, 3 A. veronii biovar sobria, 8 A. hydrophila, 3 A. caviae ve 1 A. dhakensis) suşlarının antibiyogramı, antimikrobiyal direnç genleri ve integronları çalışılmıştır. Suşların amoksisilin'e $\% 100,00$, nalidiksik asit'e \%100,00, oksitetrasiklin'e \%100,00, ampisilin'e \%93,02, tetrasiklin'e $\% 74,42$, rifampisin'e \%67,44 ve imipenem'e \%65,15 oranında dirençli oldukları bildirilmiştir. Araştırmamızda da Hossain vd. (2019)'a benzer olarak oksitetraksiklin'e 19 suşun $(\% 90,47)$, ampisilin'e 21 suşun $(\% 100,00)$ direnç gösterdiği bulunmuştur. Araştırma sonucumuzda Hossain vd. (2019)'den farklı olarak nalidiksik asit'e sadece 5 suşun $(\% 23,80)$ direnç gösterdiği saptanmıştır.

Radu vd. (2003) balıklarda Aeromonas hastalıklarında antibiyotik direncini araştırmış ampisilin, karbenisilin, eritromisin ve streptomisine karşı oldukça dirençli olduğunu bildirmiştir. Araştırmamızda da Radu vd. (2003) çalışmasıyla benzer olarak ampisiline karşı 21 suşla yüksek direnç görülürken söz konusu çalışmadan farklı olarak A. hydrophila suşlarının streptomisine karşı duyarlı olduğu, eritromisine karşı orta derecede duyarlı olduğu belirlenmiştir.

Aeromonas suşları genel olarak amioglikozitlere duyarlı olarak bilinmektedir (Laith ve Najiah, 2013). Akşit ve Kum (2008) test ettikleri Aeromonas suşlarının tamamının gentamisine duyarlı olduğunu saptamışlardır. Araştırmamızdaki sonuçlarda da benzerlik söz konusu olup bir aminoglikozit olan gentamisine karşı suşların \%95,23'i (20 suş) gentamisine duyarlı olduğu saptanmıştır.

Durmaz ve Türk (2009) streptomisin, oksitetrasiklin ve nitrofurantoin gibi antibiyotiklere karş1 Motil Aeromonaslar'ın oldukça direnç kazandıklarını saptamıştır. Araştırmamızda benzer şekilde oksitetrasiklin'e ve nitrofurantoin'e karşı direnç görülmüştür ancak farklı olarak streptomisin'e duyarlı olduğu görülmüştür.

Del Castillo vd. (2013) A. hydrophila'nın ÇAD plazmitini taşıdığını belirlediğini bildirmiştir. Araştırmada da 28 antibiyotikten 14'üne karşı suşların geliştirdiği çoklu antibiyotik direncinin tespiti bu ifadeyi desteklemektedir.

Zhu vd. (2020) tarafindan A. hydrophila'nın neden olduğu septiseminin tedavisinde ÇAD probleminin son on yılda katlanarak arttığını ve endişe verici bir orana ulaştığını bildirerek hasta balıklardan izole ettikleri suşların antibiyotik hassasiyetlerinin tüm suşlarda farklılık gösterdiğini her 
suşun farklı bir antibiyotiğe dirençli olduğu rapor edilmiştir. Yapılan bu çalışmada da benzer bir durum söz konusu olup her suşun farklı bir antibiyotiğe dirençli olduğu bulunmuş ve bu dirençli suşların antibiyotik sayısının toplam kullanılan antibiyotik sayısına oranıyla 14 antibiyotiğe çoklu antibiyotik direnci geliştirdiği saptanmıştır.

Araştırmamızda suşların ÇAD indekslerine bakıldığında sülfadiazin (9 suş), oksitetrasiklin (19 suş), oksasilin (21 suş), apramisin ( 7 suş), klindamisin (20 suş), tilosin (20 suş), sefalotin (17 suş), pristinamisin ( 15 suş), nitrofurantoin (13 suş), sülfametaksazol/trimetoprim (6 suş), oksolinik asit (17 suş), ampisilin (21 suş), vankomisin (21 suş), penisilin G (21 suş) antibiyotiklerine karş1 A. hydrophila suşlarının çoklu antibiyotik direncinin olduğu belirlenmiştir.

Thenmozhi vd. (2014) 21 A. hydrophila suşu 12 antibiyotiğe karşı test etmişler ve A. hydrophila suşlarının çoklu antibiyotik direncinin varlığını göstermiş̧ledir. 21 suşun tamamının ampisilin'e $0,5-1,0$ ÇAD indeksiyle en yüksek çoklu antibiyotik direnci gösterirken siprofloksasin'e 0,1 suşun ve gentamisin'e 0,07 karşı çoklu antibiyotik direnç göstermediğini bildirmişlerdir. Araştırma sonuçlarımız A. hydrophila suşlarının ampisilin'e 0,75 çoklu direnç gösterip siprofloksasin'e 0,3 ve gentamisin'e 0,14 karşı çoklu antibiyotik direnç geliştiremediğinin tespitiyle Thenmozhi vd. (2014) bulgularını desteklemektedir.

Kaskhedikar ve Chhabra, (2010) aminoglikozidler, sefalosporinler, nitrofurantoin, fluroquinolones, kloramfenikol, sülfonamidler, tetrasiklinler, penisilin ve polimiksin olmak üzere 9 farkl1 antibiyotik grubuna ait 14 antibiyotiğe karşı $A$. hydrophila suşlarının antibiyogram testini yapmışlar ve tüm $A$. hydrophila suşlarında çoklu antibiyotik direnci olduğunu bildirmişlerdir. Araştırmamızda da benzer durum söz konusu olup nitrofurantoin'e 0,46 indeksiyle, tetrasiklin'e 0,67 indeksiyle, penisilin'e 0,75 indeksiyle bu antibiyotiklere karşı 0,2 indeksinin üzerinde sonuçların bulunmasıyla çoklu antibiyotik direnci tespit edilmiştir ve Kaskhedikar ve Chhabra, (2010) bulgularını desteklemektedir.

Araştırma bulgularımızla A. hydrophila bakterisin yüksek oranda çoklu antibiyotik dirençliliği taşıdığı görülmüştür. Söz konusu bakterinin dirençlilik genleri açısından taşıyıcı olması nedeniyle, gen transfer yöntemleriyle sahip oldukları dirençlilik genlerini fırsatçı diğer bakterilere aktarması açısından ciddi tehdit oluşturmaktadır.

Onuk vd. (2017) farklı oranlarda antibiyotik direncinin saptanmış olması hem balık hem de insan hastalıklarının tedavisinde uygun antimikrobiyal ajanların seçilmesinin önemini ortaya koymakla birlikte Aeromonas türleri için etkin ulusal antimikrobiyal direnç izleme sistemlerine ihtiyaç duyulduğunu bildirmişlerdir. Araştırmamızda da benzer durum söz konusu olup farklı oranlarda ilaç direnci tespit edilmiştir ve sonuçlarımız Onuk vd. (2017)'nin bu ifadesini desteklemektedir.

Theguardian (2020), antibiyotik direnci hakkında yapılan araştırmalar kapsamında yeni antibiyotikler geliştirilemezse, 2050 yılına kadar her yıl 10 milyon canlının hastalıklardan dolayı risk altında olabileceği konusunda uyarıda bulunmuşlardır. Öte yandan en güçlü veya en zeki olan değil, değişime en çok uyum sağlayabilen hayatta kalır ifadesini bildiren Megginson (1963) bakterilerde çevrenin değişimine uyum sağlamış antibiyotik direncini neredeyse zirveye çıkarmıştır. Günümüzde 400 farklı mikroorganizmaya ait 20.000'in üzerinde potansiyel direnç geninin ( $\mathrm{R}$ geni) varlığ bilinmekte olup (Aksoy, 2015) antibiyotik direnci sadece bugünü değil geleceği de ilgilendiren ve tüm dünyayı tehdit eden önemli bir sorundur. Biyofilm matriksinde bulunan ve enfeksiyona neden olan bakterilerin antibiyotik dirençlilik problemi, yüz yüze kaldığımız büyük problemlerden birisidir (Costerton vd., 1999).

Antibiyotiklere bu denli direnç kazanmış A. hydrophila'yla savaşta artık yeni önlemlerin geliştirilmesi ve söz konusu patojen üzerinde fenomen stratejilerin denenmesi şarttır. Hastalıklarla mücadelede yeni stratejilerin geliştirilerek denenme süreci devam ederken bu araştırma sorusunun sonuçlarıyla hastalıkların tedavisinde doğru antibiyotik seçimine yön verileceği ve hastalığın tedavi sürecine katkı sağlayacağı kanaatindeyiz.

Teşekkür: Bu çalışma doktora tezinden özetlenmiştir. Türkiye Bilimsel ve Teknolojik Araştırma Kurumu (TÜBİTAK) 1002 Hizlı Destek Programı kapsamında 1190671 Proje Nosuyla desteklenmiştir. Araştırma da kullanılan A. hydrophila suşları Bursa Uludağ Üniversitesi (BUÜ)'nin, Isparta Uygulamalı Bilimler Üniversitesi (ISUBÜ)'nin ve Ondokuz Mayıs Üniversitesi (OMÜ)'nin değerli Öğretim Elemanları tarafından temin edilmiş olup kendilerinin şahıslarına ve bağlı bulundukları Üniversitelerine teşekkürlerimizi sunarız. 


\section{KAYNAKLAR}

Agger, W.A., McCormick, J.D., \& Gurwith, M.J. (2018). Aeromonas hydrophila ilişkili ishalin klinik ve mikrobiyolojik özellikleri. Journal Clinical Microbiology.

Aksoy, A. (2015). Antibiyotik Direnci Özel Sayısı. Türkiye Klinikleri Veteriner Bilimleri-Farmakoloji ve Toksikoloji-Özel Konular, 15(1).

Akşit, A., \& Kum, V. (2008). Gökkuşağı Alabalıkları (Oncorhynchus mykiss, Walbaum 1792)'nda sık görülen patojen mikroorganizmaların tespiti ve antibiyotik duyarlılık düzeylerinin belirlenmesi. Yüzüncü Y1l Üniversitesi Veteriner Fakültesi Dergisi, 19(1), 1-7.

Alcaide, E., Blasco, M.D., \& Esteve, C. (2005). Occurrence of drug-resistant bacteria in two European eel farms. Applied and Environmental Microbiology, 71(6), 3348-3350. https://doi.org/10.1128/AEM.71.6.33483350.2005

Altwegg, M., \& Jöhl, M. (1989). Isolation frequency of Aeromonas species in relation to patient age, Notes, 6, 55.

Andersson, D. I., Balaban, N. Q., Baquero, F., Courvalin, P., Glaser, P., Gophna, U., ... \& Tønjum, T. (2020). Antibiotic resistance: turning evolutionary principles into clinical reality. FEMS Microbiology Reviews, 44(2), 171-188.

Angulo, F.J., \& Griffin, P.M. (2000). Changes in antimicrobial resistance in Salmonella enterica serovar Typhimurium. Emerging Infectious Diseases Journal, 6, 436-438.

Angulo, F.J., Nargund, V.N. \& Chiller, T.C. (2004). Evidence of an association between use of anti-microbial agents in food animals and anti-microbial resistance among bacteria isolated from humans and the human health consequences of such resistance. Journal of Veterinary Medicine, 51(8-9), 374-379. https://doi.org/10.1111/j.1439-0450.2004.00789.x

Austin, B., \& Austin, D.A. (2016). Bacterial fish pathogens. 6. th edition. Springer International Publishing, Switzerland, pp: 21-82, 161-321, 323-396, 643-721.

Ausubel, F., Brent, R., Kingston, R., Moor, D., Seidman, J., Smith, J., \& Stauhle, K. (1988). Current Protocols in Molecular Biology. New York: Wiley Intersciences.

Baran, I., Timur, M., Aydın, N., İstanbulluoğlu, E. and Aydintuğ, M.K. 1980. Çifteler-Sakaryabaşı balık üretim ve araştırma istasyonunda, alabalıklarda (Salmo gairdneri) görülen bakteriyel hemorajik septisemi hastalığı üzerine incelemeler. Ankara Üniversitesi Veteriner Fakültesi Dergisi, 27(1), 467-473.

Boran, H., Terzi, E., Altinok, I., Capkin, E. and Bascinar, N. 2013. Bacterial diseases of cultured mediterranean Horse mackerel (Trachurus mediterraneus) in sea cages. Aquaculture, 396, 8-13.

Cabello, F.C. (2006). Heavy use of prophylactic antibiotics in aquaculture: a growing problem for human and animal health and for the environment. Environmental microbiology, 8(7), (pp. 1137-1144). https://doi.org/10.1111/j.1462-2920.2006.01054.x

Cappuccino, J.G., \& Sherman, N. (1992). Biochemical activities of microorganisms. In: Microbiology, A Laboratory Manual. The Benjamin/Cummings Publishing Co. California, USA. 76 s.

Castro, G. (2002). Characterisation of Aeromonas spp. isolated from frozen fish intended for human consumption in Mexico, International Journal of Food Microbiology, 2612, 1-9.

Clark, N.M., \& Chenoweth, C.E. (2003). Aeromonas infection of the hepatobiliary system: Report of 15 cases and review of the literature. Clinical Infectious Diseases, 37, 506-13.

CLSI (Clinical and Laboratory Standards Institute), (2017). Performance standards for antimicrobial susceptibility testing. 27th ed., CLSI Supplement M100, USA.

Costerton, J.W., Stewart, P.S., Greenberg, E.P. (1999). Bacterial Biofilms: A common Cause of Persistent Infections, Science, 284, 1318-1322.

Davies, A., Capell, C., Jehanno, D., Nychas, G.J.E., \& Kirby, R.M. (2001). Incidence of Foodborne Pathogens on Europen Fish, Food Control, 12, 67-71.

Del Castillo, C. S., Hikima, J. I., Jang, H. B., Nho, S. W., Jung, T. S., Wongtavatchai, J., ... \& Aoki, T. (2013). Comparative sequence analysis of a multidrug-resistant plasmid from Aeromonas hydrophila. Antimicrobial Agents, 57(1), 120-129.

Duman, M. (2017). Gökkuşağı Alabalıklarında Görülen Motil Aeromonas (Aeromonas hydrophila, A. sobria, A. caviae), Yersinia ruckeri ve Lactococcus garvieae Bakterilerinin Antimikrobiyal Duyarlılıkları ve Duyarlılıkta Rol Oynayan Genlerin Tespiti. Doktora Tezi, T.C. Uludağ Üniversitesi Sağlık Bilimleri Enstitüsü.

Durmaz, Y. \& Türk, N. (2009). Alabalık İşletmelerinden Motil Aeromonasların İzolasyonu ve Antibiyotiklere Duyarlılıklarının Saptanması, Kafkas Üniversitesi Veteriner Fakültesi Dergisi, Research Article, 15(3), 357-361.

Ehinmidu, J.O. (2003). Antibiotics Susceptibility Patterns of Urine Bacterial Isolates in Zaria, Nigeria. Tropical Journal of Pharmaceutical Research, 2(2), 223- 228.

Erer, H. (2002). Balık Hastalıkları. 2. baskı, Selçuk Üniv. Basimevi, Konya.

Gatesoupe, F.J. (1999). The use of probiotics in aquaculture. Aquaculture, 180, 147- 165. 
Gudding, R., Lillehaug, A., \& Evensen, Ø., (1999). Recent developments in fish vaccinology. Veterinary Immunology and Immunopathology, 72, 203-212.

Güvener, R.P. (2001). A study on the diagnosis of the aeromonad enfections in some aquarium fishes. Msc. thesis. Istanbul University.

Heppell, J., \& Davis, H.L. (2000). Application of DNA Vaccine Technology to Aquaculture. Advanced Drug Delivery Reviews, 43, 29-43.

Hossain, S., Dahanayake, P.S., De Silva, B.C.J., Wickramanayake, M.V.K.S., Wimalasena, S.H.M.P., \& Heo, G.J. (2019). Multidrug resistant Aeromonas spp. isolated from zebrafish (Danio rerio): antibiogram, antimicrobial resistance genes and class 1 integron gene cassettes. Letters in applied microbiology, 68(5), 370-377.

Kaskhedikar, M., \& Chhabra, D. (2010). Multiple drug resistance in Aeromonas hydrophila isolates of fish. Food Microbiology, 28, 157-168.

Ko, W.C., Lee, H.C., Chuang, Y.C., Liu, C.C., \& Wu, J.J. (2000). Clinical features and therapeutic implications of 104 episodes of monomicrobial Aeromonas bacteremia. Journal of Infectious, 40, 267-73.

Korun, J., \& Toprak, H.B. (2010). Kültürü yapılan gökkuşağı alabalıkları (Oncorhynchus mykiss)'nin bağırsağından izole edilen hareketli Aeromonas suşlarının antibiyotik hassasiyetleri üzerine NACl'un etkisi. Kafkas Üniversitesi Veteriner Fakültesi Dergisi, 16(2), 193-198.

Krumperman, P.H. (1983). Multiple Antibiotic Resistance Indexing of Escherichia coli to Identify HighRisk Sources of Fecal Contamination of Food. American Society for Microbiology, Applied Environmental Microbiology, 46(1), 165-170.

Kusdarwati, R., Kurniawan, H., \& Prayogi, Y.T. (2017). Isolation and identification of Aeromonas hydrophila and Saprolegnia sp. on catfish (Clarias gariepinus) in floating cages in Bozem Moro Krembangan Surabaya. In IOP Conference Series: Earth and Environmental Science, 55(1) p. (012038). IOP Publishing.

L'Abee-Lund, T.M., \& Sorum, H. (2001). Class 1 integrons mediate antibiotic resistance in the fish pathogen Aeromonas salmonicida worldwide. Microbial Drug Resistance, 7(3), 263-272. https://doi.org/10.1089/10766290152652819.

Laith, A.R., \& Najiah, M. (2013). Aeromonas hydrophila: antimicrobial susceptibility and histopathology of isolates from diseased catfish, Clarias gariepinus (Burchell). Journal of Aquaculture Research and Development, 5(2), 1-7. https://doi.org/10.4172/2155-9546.1000215.

Lasee, B. A., (1995). Introduction To Fish Healt Management, U.S. Fish and Wildlife Service La Crosse Fish Healt Center 555, Lester Avenue Onalaska, Wisconsin, 54650.

Lehone, L., \& Rawlin, G.P. (2000). Fish Diseases and Human Health in Aquaculture, Medical Journal of Australia, 173(5), 256-259.

Lukistyowati, I. (2012). Pelacakan Gen Aerolysin dari Aeromonas hydrophila pada Ikan Mas yang Diberi Pakan Ekstrak Bawang Putih (Detection of Aerolysin Gen orom Aeromonas hydrophila In Common Carp Fed With Garlic Extract). Jurnal Veteriner Maret, 13(1), 43-50.

Mancini, M.A., Galetto, M., \& Gonzalez Quintana, H. (1997). Identification, clinical signs and histopathological lesions of Aeromonas hydrophila in fishes (Odontesthes bonariensis). Revista de Medicina Veterinaria Buenos Aires, 78(1), 65-68.

Mathewson, J.J., \& Dupont, H.L. (1992). Aeromonas species: role as human pathogens, In: Remington, J.S., Swartz, M.N. (eds.), Current Clinical Topics in Infectious Diseases, Vol12e. Cambridge: Blackwell Scientific. pp 26-36.

Matyar, F. (2016). Hastane Kanalizasyonlarından İzole Edilen Gram-negatif Bakterilerin Tiplendirilmesi ve Çoklu Antibiyotik Dirençliliklerinin Saptanması. Türk Tarım - Gıda Bilim ve Teknoloji Dergisi, $4(10), 845-849$.

Mueller, H.J. \& Hinton, J. (1941). A protein-free medium for primary isolation of the Gonococcus and Meningococcus. Proceedings of the Society for Experimental Biology and Medicine, 48, 330-333.

Naylor, R., \& Burke, M. (2005) Aquaculture and ocean resources: raising tigers of the sea. Annual Review of Environment and Resources, 30,185-218.

Onuk, E.E., Findık, A., Turk, N., Altun, S., Korun, J., Ozer, S., Avsever, M.L. ve A. Ciftci, "Molecular identification and determination of some virulence genes of Aeromonas spp. in fish and water from Turkish coastal regions." Revue de Medecine Veterinaire 164 (4): 200-206. (2013)

Onuk, E.E., Tanrıverdi Çaycı, Y., Çoban, A.Y., Çiftci, A., Balta, F., Didinen, B.I., \& Altun, S., (2017). Balık ve yetiştirme suyu kökenli Aeromonas izolatlarının antimikrobiyal duyarlılıklarının saptanması. Kısa Bilimsel Çalışma/Short Communication, Ankara Üniversitesi Veteriner Fakültesi Dergisi, 64, 69-73.

Öztürk, R.Ç., \& Altınok, İ. (2014). Bacterial and viral fish diseases in Turkey. Turkish Journal of Fisheries and Aquatic Sciences, 14(1), 275-297.

Öztürk, D., Adanır, R., \& Turutoğlu, H. (2007). Bir sazan (Cyprinus carpio) işletmesinde Aeromonas hydrophila izolasyonu ve antibiyotik duyarlılığı. Ulusal Su Ürünleri Sempozyumu, at Mugla. 
Paul, S., Bezbaruah, R.L., Roy, M.K., \& Ghosh, A.C. (1997). Multiple antibiotic resistance (MAR) index and its reversion in Pseudomonas aeruginosa. Letters in Applied Microbiology, 24, 169-171.

Petersen, A, Andersen, J.S., Kaewmak, T., Somsiri, T., \& Dalsgaard, A. (2002). Impact of integrated fish farming on antimicrobial resistance in a pond environment. Appliend and Environmental Microbiology, 68, 6036-6042.

Poobalane, S., Thompson, K.D., Ardo, L., Verjan, N., Han, H.J., \& Jeney, G. et. al. (2010). Production and efficacy of an Aeromonas hydrophila recombinant S-layer protein vaccine for fish. Vaccine, 28, 3540-7.

Radu, S., Ahmad, N., Ling, F.H., \& Reezal, A. (2003). Prevalence and resistance to antibiotics for Aeromonas species from retail fish in Malaysia. International Journal of Food Microbiology, 81(3), 261-266. https://doi.org/10.1016/s0168-1605(02)00228-3.

Rasko, D., \& Sperandio, V. (2010). Anti-Virulence Strategies to Combat Bacteria-Mediated Disease, Nature Reviews Drug Discovery, 9, 117-128.

Rehulka, J. (2002). Aeromonas causes severe skin lesions in Rainbow trout, Clinical pathology, haemotology and biochemistry, Research Institute of Fish Culture and Hydrobiology, 71, 351-360.

Roberts, R.J., \& Shepherd, C.J. (2001). Alabalık ve Salmon Hastalıkları (Handbook of Trout and Salmon Diseases), (Çevirmen: Vatansever, H.). Akademi-UĞURER Tarımsal Kitap Tanıtım ve Pazarlama Hizmetleri, Kayseri, s.254.

Sağlam, Y.S., Işık, N., Arslan, A., \& Erer, H. (2006). Erzurum Bölgesindeki Gökkuşağı Alabalıklarında (Oncorhynchus mykiss W. 1792) Aeromonas hydrophila ve Yersinia ruckeri İzolasyonu ve Patolojik İncelemeler. Atatürk Üniversitesi Veteriner Bilimleri Dergisi, 1(1-2), 6-10.

Sakai, M. (1999). Current status of fish immunostimulants. Aquaculture, 172, 63-92.

Sarkodie, E.K., Zhou, S., \& Chu, W. (2019). N-Acylhomoserine Lactones (AHLs), QseB/C Gene Detection, Virulence Factors and Antibiotics Resistance of Aeromonas hydrophila.Advances in Microbiology, 9(05), 495.

Sorum, H. (2006) Antimicrobial drug resistance in fish pathogens. In Antimicrobial Resistance in Bacteria of Animal Origin. Aarestrup, F.M. (ed.). Washington, DC, USA: American Society for Microbiology Press, pp. 213-238 (Chapter 13).

Theguardian, (2020). Antibiotics Powerful antibiotic discovered using machine learning for first time, https://www.theguardian.com/society/2020/feb/20/antibiotic-that-kills-drug-resistant-bacteria-discoveredthrough-ai Son erişim tarihi: 01.08.2020.

Thenmozhi, S., Rajeswari, P., Kumar, B. S., Saipriyanga, V., \& Kalpana, M. (2014). Multi-drug Resistant Patterns of Biofilm Forming Aeromonas hydrophila from Urine Samples. International Journal of Pharmaceutical Sciences and Research, 5(7), 2908.

Timur, M. (1983). An outbreak of disease of farmed eel (Anguilla anguilla) due to Aeromonas hydrophila in Turkey. Histopathological and bacteriological studies. Ankara Üniversitesi Veteriner Fakultesi Dergisi, 30(3), 361-367.

Uttley, A.H., Collins, C.H., Naidoo, J., George, R.C. (1988). Vancomycin-resistant enterococci, The Lancet, 1, 57-58.

Werner, S.B., \& Rutherford, G.W. (1990). Aeromonas wound infections associated with outdoor activities California, California Department of Health Care Services, 39(20), 334-335.

Witte, W. (2000). Selective pressure by antibiotic use in livestock. International Journal of Antimicrobial Agents, 16, S19-S24.

Zhu, W., Zhou, S., \& Chu, W. (2020). Comparative proteomic analysis of sensitive and multi-drug resistant Aeromonas hydrophila isolated from diseased fish. Microbial Pathogenesis, 139, 103930. https://doi.org/10.1016/j.micpath.2019.103930. 